\title{
Reversal of rocuronium induced neuromuscular blockade using sugammadex in a patient with eclampsia treated by magnesium intraoperatively
}

\author{
Sejin Song, Byung Hoon Yoo, Kye-Min Kim, and Sangseok Lee \\ Department of Anesthesiology and Pain Medicine, Sanggye Paik Hospital, Inje University College of Medicine, Seoul, Korea
}

Magnesium has been used frequently both as an anticonvulsant for preeclampsia and in the treatment of preterm labor. Magnesium also results in potentiation of the effects of neuromuscular blocking drugs, and attenuates their reversal with anticholinesterase [1]. Prolongation of the duration of the neuromuscular blockade (NMB) increases the risk of residual paralysis. Unlike anticholinesterase, sugammadex binds steroidal muscle relaxants by encapsulation, and it can rapidly and completely antagonize the action of the NMB. Theoretically, magnesium sulfate may reduce the efficacy of sugammadex [2]. We report a successful reversal of NMB with sugammadex in a patient with eclampsia who was treated with magnesium intraoperatively and showed incomplete reversal with anticholinesterase from rocuronium-induced NMB.

A 30-year-old multipara (height $167 \mathrm{~cm}$, weight $62 \mathrm{~kg}$ ) at 27 weeks and 5 days of gestation visited the emergency room (ER) complaining of epigastric soreness, nausea, vomiting, and headache since the previous night. She had no specific medical history. Her blood pressure was $200 / 124 \mathrm{mmHg}$, heart rate 86 beats/min, and respiratory rate 24 breaths/min. According to a non-stress test, the fetal heart rate was 150 beats/min. After intravenous administration of hydralazine $5 \mathrm{mg}$, her blood pressure decreased to $140 / 100 \mathrm{mmHg}$. Forty minutes later, a seizure occurred. Diazepam $10 \mathrm{mg}$ was immediately administered intravenously, and just an hour after the patient's arrival at the ER, an emergency cesarean section was performed under general anesthesia.
When the patient arrived in the operating room, she was drowsy and free of convulsions. Standard monitoring and continuous invasive arterial blood pressure monitoring were initiated. Before the induction of anesthesia, the patient's blood pressure was 175/116 $\mathrm{mmHg}$, heart rate was 144 beats/min, and peripheral oxygen saturation was $100 \%$. After the induction of anesthesia with thiopental sodium $4 \mathrm{mg} / \mathrm{kg}$ and succinylcholine $1 \mathrm{mg} / \mathrm{kg}$, intubation was performed, and $30 \mathrm{mg}$ of rocuronium was additionally administered to maintain muscle relaxation. Anesthesia was maintained with oxygen, nitrous oxide, and 1-2 vol\% sevoflurane. A male neonate with a body weight of 1,030 $\mathrm{g}$ was delivered at six minutes after incision. The Apgar scores were $2 / 3 / 7$ at $1 / 5 / 10$ minutes after birth, respectively.

After delivery, oxytocin $20 \mathrm{IU}$ was mixed with $1,000 \mathrm{ml}$ of Hartman's solution and given intravenously. Magnesium sulfate $60 \mathrm{mg} / \mathrm{kg}$ was also administered using an infusion pump for 30 minutes for postoperative prophylaxis. Fentanyl $100 \mu \mathrm{g}$ was administered for postoperative pain control. Thirty-five minutes after the administration of rocuronium, neostigmine $0.05 \mathrm{mg} /$ $\mathrm{kg}$ and glycopyrrolate $0.006 \mathrm{mg} / \mathrm{kg}$ were administered for the reversal of muscle relaxation. However, even at 12 minutes past the administration of the reversal agent, the patient's respiration was weak. Neuromuscular monitoring (TOF-WATCH ${ }^{\circledR}$, Organon, Dublin, Ireland) showed a count of three (T3) in response to train-of-four (TOF) stimulation. Therefore, we decided to give sugammadex $2 \mathrm{mg} / \mathrm{kg}$ IV. The TOF ratio became 0.75 at 40 seconds after sugammadex administration. After confirming

Corresponding author: Sangseok Lee, M.D., Department of Anesthesiology and Pain Medicine, Sanggye Paik Hospital, Inje University College of Medicine, 1342, Dongil-ro, Nowon-gu, Seoul 130-707, Korea. Tel: 82-2-950-1171, Fax: 82-2-950-1323, E-mail: s2248@paik.ac.kr

(c) This is an open-access article distributed under the terms of the Creative Commons Attribution Non-Commercial License (http:// creativecommons.org/licenses/by-nc/3.0/), which permits unrestricted non-commercial use, distribution, and reproduction in any medium, provided the original work is properly cited. 
full recovery by TOF ratio as $100 \%$, the patient was extubated uneventfully and transferred to the intensive care unit (ICU) to allow monitoring of the occurrence of convulsions and other events. Plasma magnesium concentration measured at arrival in the ICU was $>1.95 \mathrm{mM}$. The total operation time was $35 \mathrm{~min}-$ utes and the patient remained under anesthesia for one hour. The patient was discharged from the hospital eight days later, and regular follow-up was continued.

An excess of magnesium has both pre-synaptic and post-synaptic effects on the neuromuscular junction [3]. Pre-synaptically, it decreases the amount of acetylcholine which is liberated at the motor nerve terminals through inhibition of voltage-dependent $\mathrm{P} / \mathrm{Q}$-type calcium channels. It diminishes the depolarizing action of acetylcholine at the end plate. Post-synaptically, it depresses the excitability of the muscle fiber membrane. Magnesium alone can induce significant NMB only at high plasma concentrations (5 to $10 \mathrm{mM}$ ) [3]. However, in the presence of neuromuscular blocking agents, much lower concentrations of magnesium ( $\geq 1 \mathrm{mM}$ ) may inhibit neuromuscular transmission because in this case more acetylcholine is needed to produce a normal degree of depolarization at the end plate [2,3]. Under the influence of magnesium, the prediction of recovery from NMB with anticholinesterase may be difficult. Gaiser and Seem [4] reported that the expected duration of NMB by rocuronium was prolonged four-fold (215 minutes) with magnesium treatment. Therefore, complete reversal of NMB with sugammadex is regarded to be a more secure method. In our case, the postop- erative plasma magnesium concentration was $>1.95 \mathrm{mM}$, which can lead to inhibition of neuromuscular transmission. The NMB was successfully reversed by sugammadex.

Czarnetzki et al. [5] conducted a randomized controlled trial to confirm the efficacy of sugammadex for the reversal of moderate and deep rocuronium-induced NMB in patients pretreated with intravenous magnesium. They concluded that pretreatment with a single intravenous dose of magnesium sulfate $60 \mathrm{mg} / \mathrm{kg}$ does not decrease the efficacy of recommended doses of sugammadex for the reversal of moderate and deep NMB induced by an intubation dose of rocuronium. Unlike in that report, we administered magnesium 30 minutes before the end of surgery. It is possible that the plasma concentration of magnesium in our patient may be higher than that of Czarnetzki's report at the time of the end of the operation. However, the efficacy of the recommended dose of sugammadex was unchanged and showed the same effect. In some cases, under high plasma concentrations of magnesium, one should be aware that decreases in the efficacy of sugammadex could occur. Therefore, NMB reversal should be attempted carefully under quantitative neuromuscular monitoring, taking into account the dose of magnesium, the timing of its administration, and serum concentrations.

In conclusion, the administration of sugammadex $2.0 \mathrm{mg} / \mathrm{kg}$ in a pregnant woman who was treated with magnesium $60 \mathrm{mg} / \mathrm{kg}$ intraoperatively demonstrated effective and complete reversal of rocuronium-induced NMB in the case of incomplete recovery with administration of anticholinesterase.

\section{References}

1. Czarnetzki C, Lysakowski C, Elia N, Tramer MR. Time course of rocuronium-induced neuromuscular block after pre-treatment with magnesium sulphate: a randomised study. Acta Anaesthesiol Scand 2010; 54: 299-306.

2. Bom A, Hope F, Rutherford S, Thomson K. Preclinical pharmacology of sugammadex. J Crit Care 2009; 24: 29-35.

3. Del Castillo J, Engbaek L. The nature of the neuromuscular block produced by magnesium. J Physiol 1954; 124: 370-84.

4. Gaiser RR, Seem EH. Use of rocuronium in a pregnant patient with an open eye injury, receiving magnesium medication, for preterm labour. Br J Anaesth 1996; 77: 669-71.

5. Czarnetzki C, Tassonyi E, Lysakowski C, Elia N, Tramèr MR. Efficacy of sugammadex for the reversal of moderate and deep rocuroniuminduced neuromuscular block in patients pretreated with intravenous magnesium: a randomized controlled trial. Anesthesiology 2014; 121: 59-67. 